\title{
A ICONOGRAFIA LINEAR DA EVOLUÇÃO NA PERSPECTIVA DE DOCENTES QUE ATUAM NA EDUCAC̣̃̃O BÁSICA
}

\author{
PATRÍCIA DA SILVA SANTOS ${ }^{*}$ \\ https://orcid.org/0000-0003-1908-1093 \\ ADRIANA PUGLIESE II"* \\ https://orcid.org/0000-0002-4683-5834 \\ CHARLES MORPHY D. SANTOS $" * \cdots$ \\ https://orcid.org/0000-0001-5577-0799
}

RESUMO: A marcha dos hominídeos tem influenciado fortemente a percepção das pessoas sobre a teoria evolutiva. Nesse artigo, analisamos se tal representação da evolução afeta a percepção dos educadores sobre Biologia e Ensino de Ciências. Através de uma pesquisa qualitativa, com a participação de professores de uma escola da periferia de São Paulo, notamos a falta de conhecimento aprofundado sobre a teoria evolutiva, suas representações iconográficas e a importância do conceito evolutivo de ancestralidade comum. Analisando as respostas de professores das Ciências Naturais e de outras áreas, percebe-se que uma abordagem interdisciplinar pouco se faz presente, afastando os educadores de um entendimento mais amplo sobre o contexto histórico das teorias científicas. A marcha do progresso parece ajudar a perpetuar a ideia da inexorabilidade do "progresso biológico", com o homem branco como estágio superior da evolução. Grande parte dos docentes parece basear sua percepção sobre ciência em noções de senso comum.

Palavras-chave: Ensino de ciências. Eugenia. Teoria evolutiva.

\section{LA ICONOGRAFÍA LINEAL DE LA EVOLUCIÓN EN LA PERSPECTIVA DE DOCENTES QUE ACTÚAN EN LA EDUCACIÓN PRIMARIA Y SECUNDARIA}

RESUMEN: La marcha de los homínidos ha influido fuertemente en la percepción de las personas acerca de la teoría evolutiva. En ese artículo, analizamos si esa representación de la evolución afecta la percepción de los educadores acerca de la Biología y Enseñanza

* Mestra em Ensino,
História e Filosofia das Ciências
e Matemática (UFABC). Professora
de Ciências da Rede Municipal
de São Paulo, SP, Brasil.
E-mail:< patyssoba@gmail.com>.
** Doutora em Educação pela
Universidade de São Paulo (USP).
Professora da Universidade Federal do
ABC, SP, Brasil. Integrante do Núcleo
de Estudos e Pesquisas em Ensino
de Ciências (NEPEC/UFABC).
E-mail: < adriana.pugliese@gmail.com>.
*** Doutor em Entomologia pela
Universidade de São Paulo (USP).
Professor Associado da Universidade
Federal do ABC, SP, Brasil.
Integrante do Laboratório de
Sistemática e Diversidade (UFABC).

\footnotetext{
' Rede Municipal de São Paulo, São Paulo, SP - Brasil.

" Universidade Federal do ABC, Santo André, SP - Brasil.
} 
de Ciencias. Por medio de investigación cualitativa, con la participación de profesores de una escuela de la periferia de San Pablo, observamos la falta de conocimiento profundizado acerca de la teoría evolutiva, sus representaciones iconográficas y la importancia del concepto evolutivo de ancestralidad común. Cuando se analizan las respuestas de profesores de las Ciencias Naturales y de otras áreas, se nota que un enfoque interdisciplinario está poco presente, alejando los educadores de un entendimiento más amplio acerca del contexto histórico de las teorías científicas. La marcha del progreso parece ayudar a mantener la idea de la inexorabilidad del "progreso biológico", con el hombre blanco como etapa superior de la evolución. Gran parte de los docentes parecen basar su percepción acerca de la ciencia en nociones de sentido común.

Palabras clave: Enseñanza de ciencias. Eugenesia. Teoría evolutiva.

\section{THE LINEAR ICONOGRAPHY OF EVOLUTION FROM PERSPECTIVES OF BASIC EDUCATION TEACHERS}

ABSTRACT: The march of hominids has strongly influenced educators' perception about the evolutionary theory. In the present study, we analyze if this representation of evolution affects educators' perception on science and science teaching. We performed a qualitative research with the participation of teachers from a school of the suburbs of São Paulo, we noted a lack of deep understanding of the theory of evolution, its iconographic representations and the importance of the evolutionary concept of common ancestry. Analyzing the answers of teachers of Natural Sciences and those of other areas, it is perceived that an interdisciplinary approach is little present, distancing educators from a broader understanding of the historical context of scientific theories. The march of progress seems to help perpetuating the idea of the inexorability of "biological progress", with the white man as the highest evolutionary stage. A great part of teachers based their perception of science in superficial and common sense notions. Keywords: Evolutionary theory. Eugenics. Science teaching. 


\section{INTRODUĈ̣̃O}

Todos os seres vivos estão historicamente conectados uns aos outros devido à ancestralidade comum: as formas orgânicas do planeta correspondem a ramos de uma grande árvore da vida (EL-HANI; MEYER, 2009). A teoria da evolução, centralizadora do conhecimento biológico, é um dos principais norteadores do Ensino de Ciências e Biologia no Brasil, segundo os Parâmetros Curriculares Nacionais (PCN) (BRASIL, 1998) e as Orientações Curriculares para o Ensino Médio, publicadas em 2006. A origem e evolução da vida devem ser discutidas de forma interdisciplinar, em um viés histórico-filosófico, que permita ao estudante compreender sua relação com os demais membros da espécie humana e com o meio ambiente (MOURA; SILVA-SANTANA, 2012). No entanto, não há um detalhamento explícito sobre o que deve ser abordado: as Orientações Educacionais Complementares aos Parâmetros Curriculares Nacionais (PCN+ Ensino Médio) apenas direcionam que a teoria evolutiva deve ser ensinada sob a ótica neodarwinista (BRASIL, 2002; VALENÇA; FALCÃO, 2012).

Mesmo com a recomendação dos PCN, geralmente a evolução é abordada brevemente nos anos finais do Ensino Fundamental e nas últimas semanas das aulas de Biologia no Ensino Médio. O pouco tempo disponível para um tratamento mais acurado destes temas, aliado à ortodoxia do material utilizado por boa parte dos professores e às deficiências na sua formação, acabam por dificultar a exposição da teoria evolutiva em sala de aula (SANTOS; KLASSA, 2012; MOURA; SILVA-SANTANA, 2012; VALENÇA; FALCÃO, 2012; BIZOTTO; GHILARDI-LOPES; SANTOS, 2016).

Para Valença e Falcão (2012), um dos aspectos que influenciam a exposição e compreensão de conceitos evolutivos é o fato de que termos como "evolução" e "adaptação" têm diversas definições. Os professores teriam dificuldade, por exemplo, em relacionar os conceitos de "gene", "variabilidade populacional", "genética de populações", "relações ecológicas", "tempo geológico" e "processos de especiação” (PEREIRA, 2009). Segundo Tidon e Lewotin (2004), 60\% dos professores do Ensino Médio de Brasília têm dificuldades em ensinar a teoria da evolução. Não são surpreendentes, portanto, os resultados de uma pesquisa realizada pelo Instituto Brasileiro de Opinião Pública e Estatística (IBOPE, 2004), segundo a qual apenas $9 \%$ dos entrevistados disseram acreditar que o homem não é uma criação divina - essa pesquisa aponta ainda que 89\% dos brasileiros gostariam que o criacionismo fosse ensinado nas escolas e 75\% que a teoria da evolução no currículo escolar deveria ser substituída pelo criacionismo.

Para agravar o quadro, uma interpretação corrente é a de que a evolução orgânica leva inexoravelmente ao melhoramento e ao "progresso" (GOULD, 1990; SANTOS; KLASSA, 2012). Essa perspectiva é explícita na imagem de primatas em fila, geralmente iniciada por um chimpanzé ou um Australopithecus e finalizada com um Homo sapiens - a sequência é uma menção à ideia de evolução linear, aperfeiçoamento com o passar do tempo e transformação de uma espécie em outra. Essa visão distorcida da teoria evolutiva traz à tona falácias como a de que "o homem veio do macaco", quando, na realidade, eles apenas compartilham um ancestral comum. Gould (1990) define esta imagem, usada largamente na 
publicidade, no humor e mesmo em livros didáticos, como "a marcha do progresso" ou a "iconografia canônica da evolução". Essa iconografia vai ao encontro da visão que boa parte dos estudantes tem sobre o conceito de evolução: um processo de aprimoramento da espécie humana (BIZZO, 1991; PEREIRA, 2009).

O objetivo central do presente trabalho é discutir a percepção de professores a respeito da iconografia canônica da evolução (cf. GOULD, 1990) e de como a evolução biológica é tida como sinônimo de progresso dos seres vivos em direção a um ideal presumido de perfeição orgânica (o Homo sapiens). Especificamente, procuramos identificar a interpretação de docentes do Ensino Fundamental regular (EF) e da Educação de Jovens e Adultos (EJA), tanto da área de Ciências quanto de outras áreas não relacionadas, sobre a iconografia da evolução e de que maneira essa percepção pode influenciar a compreensão, por parte destes, de fundamentos da teoria evolutiva e sua apresentação em sala de aula. Ainda, estabelecemos um paralelo entre as questões históricas de discriminação racial, darwinismo social e eugenia, a fim de identificar se a "marcha do progresso" evolutivo reforça essas perspectivas.

\section{PROCEDIMENTOS METODOLÓGICOS}

Foi realizada pesquisa qualitativa, direcionada a professores, composta por seis questões entregues pessoalmente aos docentes nas unidades escolares. Os sujeitos selecionados correspondem a educadores do Ensino Fundamental regular e da EJA de escolas da rede municipal da Zona Leste da cidade de São Paulo (capital), Brasil. Ainda que a abordagem da teoria da evolução aconteça principalmente no Ensino Médio, o primeiro tratamento formal sobre diversidade biológica ocorre no Ensino Fundamental. Além disso, questionamentos sobre o mundo natural por parte dos alunos são feitos durante qualquer período da vida escolar. Assim, optou-se por buscar compreender a percepção de professores dos anos fundamentais da Educação Básica, que irão preparar o educando para os níveis seguintes do ensino.

O questionário foi composto por perguntas abertas. A amostra contou com 18 docentes distribuídos em dois grupos: 6 professores de Ciências e 12 professores de outras disciplinas. O quadro 1 sintetiza a relação entre os docentes entrevistados, qual disciplina está sob sua responsabilidade na escola, a sua idade e qual o seu ciclo de atuação (se EF regular ou EJA). Apesar da folha de respostas ser anônima, foi entregue também um instrumento de coleta de dados pessoais, para compreendermos minimamente o contexto dos respondentes. O levantamento dos dados foi realizado de dezembro de 2015 a fevereiro de 2016.

Cada conjunto de respostas foi comparado ao referencial levantado, discutido aqui logo após a apresentação de cada questão na seção "Resultados e Discussão". As respostas também foram categorizadas conforme as justificativas e a relação com este referencial, estabelecendo os grupos: "satisfatório", "parcialmente satisfatório" e "insatisfatório". 
Quadro 1. Distribuição por categorias dos docentes entrevistados.

\begin{tabular}{|l|c|l|l|}
\hline \multicolumn{1}{|c|}{ Disciplina } & $\begin{array}{c}\text { Número de } \\
\text { docentes }\end{array}$ & \multicolumn{1}{|c|}{ Idade } & \multicolumn{1}{c|}{ Ciclo de atuação } \\
\hline Ciências & 6 & $30,33,34,47,45,54$ anos & $\begin{array}{l}5 \text { docentes do EF regular } \\
1 \text { docente da EJA }\end{array}$ \\
\hline História & 4 & $34,40,51,55$ anos & $\begin{array}{l}2 \text { docentes do EF regular } \\
2 \text { docentes da EJA }\end{array}$ \\
\hline Geografia & 2 & $\begin{array}{l}41 \text { anos } \\
\text { Não informado }\end{array}$ & 2 docentes do EF regular \\
\hline Português & 2 & Ambos 39 anos & 2 docentes do EF regular \\
\hline Matemática & 1 & 51 anos & 1 docente do EF regular \\
\hline Artes & 1 & 40 anos & 1 docente do EF regular \\
\hline Educação Física & 1 & 37 anos & 1 docente do EF regular \\
\hline Alfabetização & 1 & 26 anos & 1 docente do EF regular \\
\hline
\end{tabular}

Fonte: Autoria própria.

\section{RESULTADOS E DISCUSSÃO}

Os respondentes formam um grupo heterogêneo mesmo dentro de suas áreas. A média de idade dos professores que responderam às questões apresentadas neste trabalho é de 35 anos, o que permite inferir que eles tiveram a oportunidade de vivenciar o processo de expansão da internet, um dos meios que mais facilita o compartilhamento da iconografia canônica da evolução. Visto que essa é uma imagem bastante presente na literatura especializada, na divulgação científica e em mídias não acadêmicas (GOULD, 1990), é possível que os docentes respondentes da pesquisa tenham tido acessos a livros que utilizaram a iconografia como referência para o estudo das Ciências, no geral, e da teoria evolutiva, em particular.

Aqui, os professores de Ciências serão representados pela sigla PC e os de outras áreas pela sigla POA, acompanhadas de um número em ordem crescente (de PC1 a PC6 e de POA1 a POA12). Abaixo são apresentadas as questões, seguidas de uma sugestão de resposta e da discussão a respeito das respostas fornecidas pelos professores. 


\section{Questão 1: Em sua concep̧ção, o que as seguintes imagens representam?}

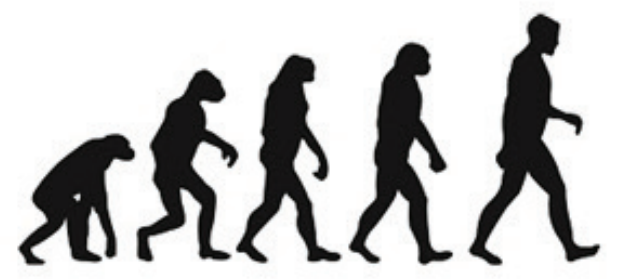

a) Sugestão de resposta: A iconografia representa a "escalada evolutiva" na visão do senso comum. Os hominídeos em fila, sendo liderados pelo Homo sapiens, representam a ideia de evolução progressiva. Dessa forma, o ser humano seria o organismo mais evoluído e o Australopithecus (ou um chimpanzé) o mais primitivo: nossa espécie representaria o ápice da evolução. Esta interpretação está incorreta. Da mesma forma, na imagem está subjacente a ideia de transformação de uma espécie em outra, mais relacionada à visão lamarckista que à darwiniana.

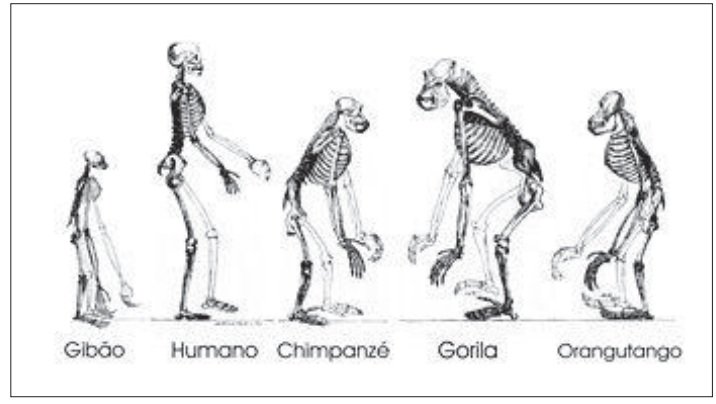

b) Sugestão de resposta: As estruturas homólogas sugerem ancestralidade comum, portanto, a imagem relaciona-se a homologia entre as partes do esqueleto dos primatas em questão, permitindo-se inferir algum grau de parentesco entre as espécies. A imagem representa a tentativa de se demonstrar a semelhança anatômica entre hominídeos.

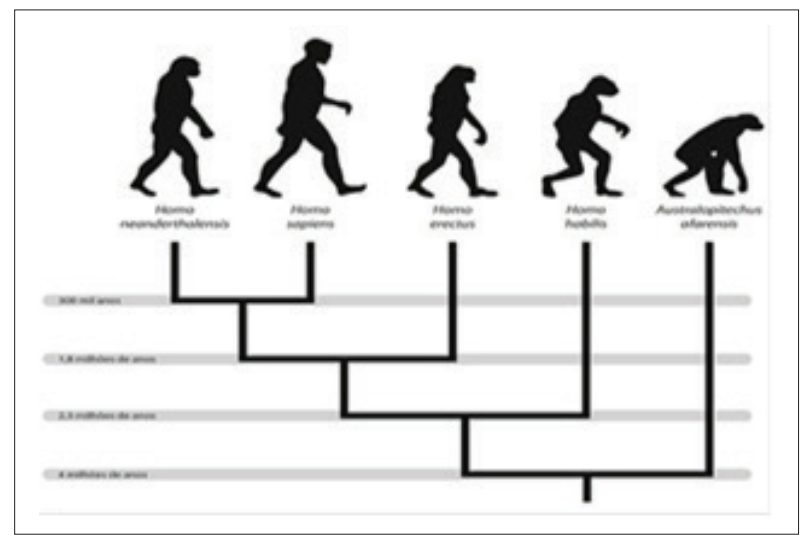


c) Sugestão de resposta: A árvore filogenética representa as relações de parentesco entre os organismos. Diferentemente da fila dos hominídeos, não há ideia de superioridade, mas sim de ramificação a partir de ancestrais comuns. A imagem demonstra a relação de parentesco entre os hominídeos aqui representados. É uma explicação gráfica da teoria da evolução, fazendo alusão à árvore evolutiva discutida por Darwin.

As três imagens apresentadas tencionavam identificar a percepção geral dos educadores sobre evolução como progresso, homologia e ancestralidade comum (DARWIN, 1859). A primeira imagem faz menção à iconografia clássica da evolução, representando a "escala evolutiva da humanidade" na visão do senso comum (GOULD, 1990), que expressa a ideia de progresso e aumento de complexidade. A segunda imagem está relacionada com homologia e ancestralidade comum, demonstrando a semelhança anatômica entre os hominídeos (HUXLEY, 1863). A terceira imagem apresenta uma hipótese de relações filogenéticas disposta em um diagrama ramificado - um cladograma -, apresentando as relações de parentesco entre as espécies e indicando que não há hierarquia progressiva (do mais simples para o mais complexo) (SANTOS; KLASSA, 2012).

As respostas sugerem que os docentes da área de Ciências possuem conhecimentos básicos sobre os conceitos de homologia e ancestralidade comum, embora lhes falte aprofundamento. Analisando suas perspectivas quanto à iconografia canônica da evolução, a maior parte (67\%) dos docentes da área de Ciências compreendeu que a imagem é uma representação equivocada da teoria evolutiva e que leva a erros de análise e interpretação (SANTOS; CALOR, 2008), embora poucos tenham conseguido justificar sua resposta. Alguns docentes relacionaram a iconografia à visão de linearidade (tal qual o transformacionismo lamarckista), considerando-a uma representação incorreta da evolução. No entanto, boa parte dos docentes de Ciências que responderam a esta pesquisa considerou explicitamente que as imagens apresentadas representam a evolução do homem a partir do macaco, uma ideia equivocada reforçada pela disseminação desta iconografia.

Quanto aos docentes das outras áreas, a maior parte respondeu à primeira questão a partir de um ponto de vista considerado do senso comum (SANTOS; CALOR, 2008), relacionando todas as imagens à evolução do ser humano, a despeito da evolução ocorrer nas populações (e não entre espécies), como Darwin já apontava no século XIX (DARWIN, 1859; MAYR, 2006). Muitos dos docentes reconhecem o que é homologia, mesmo sem utilizar este termo. Contudo, uma parcela substancial pensa que o cladograma (ou árvore evolutiva) apresentado trata somente da evolução humana. Nesta primeira questão, poucos docentes identificaram que a primeira imagem referia-se a uma percepção de senso comum. Alguns consideraram as imagens como uma demonstração gráfica da teoria da evolução num sentido de modificação do organismo mais simples para o mais complexo, o que está alinhado ao pensamento transformacionista de fundo lamarckista, sugerindo que suas análises estão balizadas em uma interpretação literal da marcha dos hominídeos.

Compreender a ancestralidade comum é reconhecer um dos fatores com os quais Darwin (1859) define a evolução. Contudo, identificar homologia e ancestralidade comum não é suficiente para uma compreensão mais robusta da teoria evolutiva. 
$\mathrm{Na}$ análise da primeira questão, notamos uma leitura superficial do significado da iconografia, indicando sua possível perpetuação como referência imagética da evolução. O desafio é como ajustar o ensino da teoria evolutiva - e sua representação nas diferentes mídias - ao chamado "pensamento em árvore" (BAUM; SMITH; DONOVAN, 2005; SANTOS; CALOR, 2008; GREGORY, 2009) em substituição à visão linear progressiva. Apesar da compreensão rasa da teoria evolutiva demonstrada pelos docentes, ela diverge do estabelecido nos PCN, que definem a evolução como eixo norteador do ensino de Ciências e Biologia (BRASIL, 1998).

Questão 2: Faça uma abordagem textual acerca da imagem abaixo, relacionando-a com seu conbecimento sobre a teoria da evolução.

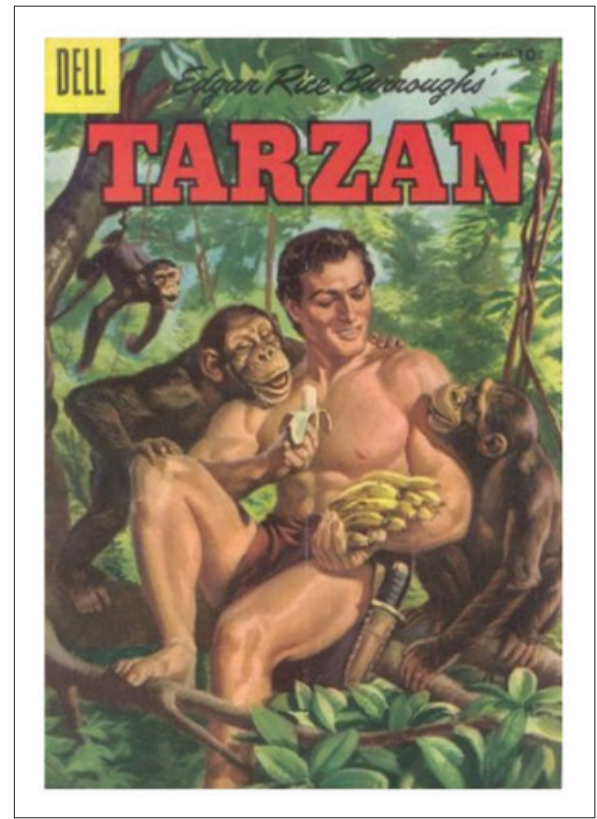

Sugestão de resposta: A figura de Tarzan representa simbolicamente o domínio do homem sobre a natureza. Essa condição de superioridade poderia justificar a exploração dos "menos aptos" (sejam humanos de outros grupos étnicos ou organismos de espécies diferentes) e do ambiente natural. A história de Tarzan, o britânico criado por macacos após a morte dos pais e que se torna o "rei da selva", reflete a ideia de hierarquia racial, sustentada por interpretações da teoria da evolução como o darwinismo social, que considera que a desigualdade entre os seres humanos é natural, ou a sociobiologia, que estuda a evolução de todo comportamento social sob a ótica adaptacionista. A imagem também pode ser associada ao colonialismo europeu entre final do século XIX e início do XX.

Diante da média de faixa etária, é possível inferir que todos os docentes tenham tido alguma experiência com a história de Tarzan. Criado em 1912 por Edgar Rice Burroughs na revista pulp All-Story Magazine, ele reflete o mito 
da existência de hierarquia racial entre as populações humanas, associada às interpretações pouco defensáveis como o darwinismo social e a sociobiologia (BLANC, 1994). O objetivo nesta questão foi analisar a possibilidade de o docente estabelecer uma analogia entre a imagem representativa (Tarzan) e a manifestação do domínio do homem branco europeu sobre a natureza e demais seres humanos, comum em livros, filmes e histórias em quadrinhos.

Nessa imagem, partiu-se da premissa de que um docente com algum conhecimento histórico e social identificaria a relação entre o personagem Tarzan e a visão eurocentrista típica do início do século XX. Uma interpretação possível da história do Tarzan é a do homem branco europeu como o "ápice da evolução humana", "conquistador" ou "mais evoluído": mesmo em um ambiente selvagem, ele continua superior aos demais seres vivos que lá habitam (CAMPOS; CRISPIM; VELEZ, n.d.). Nesse contexto, seria natural colonizar o negro africano e seu habitat, levando a ele civilização e progresso. A ideia de um homem branco "alienígena" controlando as selvas africanas, como em Tarzan, dialoga com outras representações negativas de raça, gênero e orientação sexual em diferentes produtivos de mídia, notadamente animações e filmes (TOWBIN et al., 2003). O docente de Biologia ou Ciências, ou ainda de quaisquer outras áreas do conhecimento, que tem a marcha progressiva dos hominídeos como representação imagética da teoria da evolução pode incorrer na defesa da ideia de que a presença de "civilidade" justificaria a exploração de alegadas sub-raças humanas, povos tidos como "menos evoluídos" ou minorias as mais diversas, ou naturalizar comportamentos exploratórios como produtos inevitáveis do processo evolutivo. Ainda que não ocorra a defesa ativa dessas posições em sala de aula, a falta de reflexão sobre questões relativas às representações iconográficas da evolução que reforçam estereótipos sociorraciais dificulta a desconstrução de discursos equivocados que apontam para o aparecimento do Homo sapiens branco europeizado como o objetivo final da vida no planeta.

Nenhum dos docentes da área de Ciências Naturais que respondeu à questão mencionou assuntos como exploração do meio ambiente e dos seres humanos, hierarquia racial humana e colonialismo. Nas respostas, não houve uma abordagem da condição histórica e social - em geral, os docentes apresentaram argumentos confusos envolvendo o conceito de ancestralidade comum. $O$ fato de que a ideia de superioridade entre as populações humanas (e do Homo sapiens em relação aos demais organismos) não tenha sida levantada nas respostas nos faz especular se os docentes veem como natural a ideia do homem branco apropriarse de ambientes nos quais não se encontrava em um primeiro momento, nem física nem culturalmente, e manipular os demais animais e culturas, como no caso das explorações advindas do colonialismo. A análise superficial da questão feita pelos docentes de Ciências nos faz pensar em lacunas de formação de assuntos pertencentes às ditas Ciências Humanas, ainda que estes sejam fundamentais para uma compreensão mais profunda e contextualizada das Ciências Naturais.

Os docentes das demais áreas mencionaram termos como "ancestralidade comum", associando-a, em alguns casos, a uma relação harmônica entre as espécies e características comuns (homologias). Em suas respostas, cinco docentes 
apresentaram o personagem Tarzan como homem branco civilizado e privilegiado que utiliza recursos e manipula o ambiente e os seres vivos à sua volta - para um dos docentes, "[...] a série Tarzan afirmava a superioridade do homem branco sobre o continente africano assolado pela colonização europeia no século XX”. Essa menção vem ao encontro da nossa expectativa inicial - os professores das disciplinas que não as de Ciências (Geografia e História) abordaram o tema da questão de forma mais aprofundada, ainda que não tenham feito relação direta entre o cenário da imagem de Tarzan e uma má interpretação da teoria da evolução como um dos fatores de promoção e difusão dessa perspectiva exploratória.

Analisando as respostas à questão dois e as potenciais lacunas de formação apresentadas tanto pelos docentes de Ciências quanto das demais áreas, nota-se que a interdisciplinaridade está pouco presente, o que pode se refletir também na atuação em sala de aula. A interdisciplinaridade é essencial tanto para a compreensão da evolução quanto para permitir uma integração dos conceitos na vida acadêmica e social do indivíduo. Ainda que os docentes da área de Ciências tenham apresentado maior conteúdo conceitual sobre a teoria evolutiva, a formação científica sem embasamento em questões sociais e contextos históricos fornece uma leitura parcial e "fria" do mundo. Entendemos que essa lacuna na contextualização de áreas distintas de conhecimento (Ciências Sociais e Humanas com as Biológicas) dialogue com as visões deformadas do trabalho científico propostas por Gil Pérez, Montoro, Alís, Cachapuz e Praia (2001).

É importante que, ao aprender sobre um conteúdo específico, o estudante compreenda o contexto sócio-histórico da elaboração desse conhecimento. Pouco adianta o conteúdo acabado nele mesmo: a ciência é uma atividade humana, desprovida de imparcialidade e precisa ser contextualizada para ser ensinada como disciplina escolar. Segundo Gil Pérez, Montoro, Alís, Cachapuz e Praia (2001), para compreendermos como se constroem e transformam os conhecimentos científicos é preciso assumir que o Ensino de Ciências pode transmitir certas deformações, inclusive devido à visão que o docente tem sobre a atividade de pesquisa - uma das deformações seria a visão a-problemática e a-histórica sobre a produção do conhecimento, considerando apenas o conhecimento já elaborado, sem mencionar suas limitações e os problemas que lhe deram origem.

O ensino da evolução sem o conhecimento do contexto histórico, social e filosófico em que ela foi desenvolvida (BLANC, 1994; PAUL, 2003; BOWLER, 2009) é deficiente, focado somente na questão biológica. Segundo Oleques, Santos e Boer (2011), para compreender a complexidade de biologia evolutiva é preciso abarcar conhecimentos em áreas tão distintas quanto Geologia, Paleontologia, Matemática e Filosofia. O ensino de Ciências com enfoque ecológico e evolutivo visa fazer com que os educandos percebam as relações entre diferentes disciplinas na tentativa de compreender a dinâmica do mundo vivo e suas transformações (SILVA; SILVA; TEIXEIRA, 2011).

Admitindo que o ensino de Evolução exige do professor um transitar por áreas relativamente distintas, a fim de subsidiar e ampliar a discussão, entendese esta temática curricular como momento propício de fomento da prática da alfabetização científica (AC) no ensino de Biologia. Quando Sasseron e Carvalho 
(2008, 2011) discutem sobre ensino de ciências que almeje a AC, as autoras se referem a três Eixos Estruturantes da Alfabetização Científica.

Tomando por base a proposta curricular dos PCN (BRASIL, 1998, 2002) e a teoria da evolução como eixo norteador do ensino de Biologia, defendemos que o ensino de Evolução deva ter como referência práticas pedagógicas que transitem pelos três eixos da $\mathrm{AC}$, seja em uma perspectiva de compreensão básica de termos e conceitos (eixo 1), que permitam aos estudantes deslocarem conceitos de evolução para outras áreas do conhecimento e vice e versa, seja na perspectiva de compreensão da natureza da ciência (eixo 2), exigindo que o sujeito reflita e analise conceitos e significados biológicos da temática evolutiva e qual a influência destes em atitudes cotidianas, inclusive sobre questões que mitiguem preconceitos e ideias de senso comum sobre ser "mais" ou "menos" evoluído, e, finalmente, seja o que Sasseron e Carvalho (2011, p. 76) chamam de entendimento das relações existentes entre ciência, tecnologia, sociedade e meio ambiente (eixo 3), mostrando "a necessidade de se compreender as aplicações dos saberes construídos pelas ciências considerando as ações que podem ser desencadeadas pela utilização dos mesmos".

\section{Questão 3: O que você entende acerca do termo "evolução linear"?}

Sugestão de resposta: A evolução linear refere-se à compreensão da evolução orgânica como a substituição de organismos "mais primitivos" por outros "mais evoluídos" - tal processo unidirecional culminaria no aparecimento do Homo sapiens. A ideia está relacionada à percepção da evolução como melhoramento, progresso e aumento de complexidade, tal como expressa na iconografia canônica da evolução (cf. GOULD, 1990). É uma visão equivocada da teoria evolutiva, melhor representada através de imagens de padrões ramificados (como a "árvore da vida").

No geral, os docentes da área de Ciências relacionaram o termo "evolução linear" ou "linearidade" à marcha dos hominídeos ou a aspectos correlatos. Um dos docentes citou o transformacionismo de Lamarck, ciente deste não ser mais válido no escopo da teoria da evolução. Outro mencionou que a figura da marcha trata da evolução gradual ao longo do tempo, o que também remete ao transformacionismo. Um dos docentes de Ciências relacionou a marcha dos hominídeos à percepção de melhoramento ao longo do tempo; outro ainda manifestou literalmente que evolução linear “(...) dá-se em um sentido único”.

Alguns dos docentes das outras áreas mencionaram não conhecer a expressão "evolução linear" e outros a trataram de forma literal, ou seja, "evolução em linha”. Dois grupos destacaram-se: (i) os que consideram a expressão como o significado da evolução desde o macaco até o homem, relacionando-a conscientemente com a marcha dos hominídeos; e (ii) os que destacam que a expressão "evolução linear" relaciona-se a melhoramento, progresso e civilidade. Estes docentes não mencionaram se concordam ou não com estas perspectivas.

É possível perceber que grande parte dos docentes de outras áreas desconhece a expressão "evolução linear" ou a interpreta de forma literal, como "evolução em linha” ou "em um sentido único", o que não é suficiente, per se, 
para sugerir uma compreensão mais aprofundada do seu significado. Entre os professores que responderam às questões, encontramos docentes que relacionaram a expressão com melhoramento, mas somente entre os docentes de outras áreas, encontramos menções claras e aparentemente conscientes sobre essa relação. Um dos docentes chegou a questionar se o homem de fato "(...) representa o modelo mais acabado de uma série de transformações”. Um docente fez referência à imagem da marcha dos hominídeos apresentada na primeira questão como exemplo de "evolução linear". Apesar de parecer que de alguma forma os professores de Ciências entendem que a evolução linear é uma ideia equivocada, eles não se manifestaram com propriedade sobre o assunto.

A ideia de evolução como progresso foi fortemente aceita e defendida no século XIX. Com a expansão do capitalismo industrial na Inglaterra (HOBSBAWM, 1981), a ideia de que as sociedades humanas caminhavam inexoravelmente em direção ao progresso era tida como certa, orientando Spencer no desenvolvimento do Darwinismo Social e sustentando a criação de uma cultura eugênica no final do século XIX e início do XX, com consequências nefastas tanto biológica como socialmente (BLANC, 1994; BOWLER, 2009). Além de permitir tratar destas questões em sala de aula, abordar concepções de linearidade na representação e interpretação da teoria evolutiva, principalmente com licenciandos das Ciências Biológicas (mas não apenas com estes), é uma das formas de entender a revolução causada por Darwin e o conceito de evolução ramificada-O "pensamento em árvore" (BAUM; SMITH; DONOVAN, 2005; SANTOS; CALOR, 2008; GREGORY, 2009), fortemente calcado na ideia da ancestralidade comum darwiniana.

\section{Questão 4: Você acredita que o ensino da teoria da evolução influencia a educação dos jovens de alguma maneira? Por favor, justifique sua resposta.}

Sugestão de resposta: A educação científica é importante para a compreensão do mundo e formação cidadã. A teoria da evolução, como eixo integrador para os conteúdos da área de biológicas, é base para a explicação da origem e diversificação da vida. Grande parte dos estudantes relaciona a origem da vida às questões religiosas, colocando o homem como o ser mais complexo do universo, feito à imagem e semelhança de Deus, o que poderia fazê-lo se imaginar no direito de explorar todos os recursos naturais do planeta conforme suas necessidades. Com a percepção científica da evolução biológica, o estudante pode desenvolver melhor sua relação com o ambiente e, ao ser colocado lado a lado com os demais seres vivos, perceber-se como parte da natureza.

De modo geral, os docentes da área de Ciências demonstraram acreditar que o ensino da teoria da evolução influencia a educação dos jovens, embora não tenham mencionado que o tema é um eixo integrador das Ciências Biológicas, a despeito de esta ser indicação explícita dos PCN (BRASIL, 1998, 2002). Suas respostas expressaram a importância da desconstrução do senso comum, relacionando-o, principalmente, ao criacionismo. Há uma ideia implícita de que a teoria da evolução "salva" aqueles que estão num mundo obscuro sem acesso a informações científicas, abrindo-lhes os caminhos e libertando os alunos de 
uma perspectiva criacionista da origem e diversificação da natureza. Sabemos, no entanto, que o conhecimento científico não impede - ou refuta - necessariamente a crença e a fé (GOULD, 2002; SANTOS, 2015), mas é importante que os educandos tenham conhecimento científico e condição de argumentar conscientemente acerca de suas percepções sobre o mundo e a evolução das populações biológicas.

Os docentes das outras áreas, quase em sua totalidade, mencionaram que a teoria da evolução é uma temática importante. Apresentaram justificativas diversas, dentre elas algumas questionáveis do ponto de vista científico - como a ideia de que, através da teoria evolutiva, "podermos nos preparar, enquanto espécie, para o que virá em termos de processos evolutivo", o que desconsidera o papel do acaso na evolução. Alguns dos docentes não souberam explicar porque o ensino da teoria da evolução é importante. Os argumentos mais comuns mencionaram o ensino da evolução como contraponto ao pensamento religioso. Nesse contexto, há inúmeros autores que defendem a possível existência das duas abordagens (científica e religiosa), sem que uma exclua necessariamente a outra, como Gould (2002), para quem religião e ciência funcionam como "magistérios que não se sobrepõem".

Essa visão não polarizada entre ciência e religião levantada por Gould, no contexto do ensino da teoria evolutiva, converge com o discurso de perfil conceitual discutido em diferentes estudos (MORTIMER, 1996; MORTIMER; CARVALHO, 1996; TEIXEIRA; SOBRAL, 2010), que valoriza uma negociação dos significados entre professor e alunos, admitindo que não necessariamente há substituição dos conceitos de senso comum pelos científicos. Para Mortimer (1996), as novas ideias adquiridas no processo ensino-aprendizagem devem passar a conviver com as ideias anteriores, tendo cada uma delas a possibilidade de ser empregada em um contexto conveniente.

No entanto, como não faz sentido falar sobre ciência criacionista (uma contradição em termos), a escola deve trazer para discussão o fato de entender que outras interpretações existem, mas priorizando um contexto históricoepistemológico da ciência, fomentar o ensino de evolução atrelado à educação de teorias científicas nas aulas de Ciências, e isso não deve se restringir apenas à dualidade entre as ideias de Darwin e Lamarck. Surpreendentemente, um dos docentes das outras áreas defendeu a ideia de que a divulgação da teoria evolutiva não é importante para os jovens, justificando que eles estão mais interessados em tecnologia, e afirmando que o ensino da teoria não teve impacto em si. Acreditamos que uma das causas para o discurso do referido docente possa ser o modo como o ensino da teoria evolutiva se deu em sua trajetória ainda como estudante da Educação Básica, restringindo à contraposição de ideias de Darwin e Lamarck, e na maioria das vezes ideias errôneas ou no mínimo distorcidas.

Almeida e Falcão (2010) analisaram o espaço que as teorias de Lamarck e Darwin ocupam nos livros didáticos brasileiros, apontando significativa discrepância: além de ter maior detalhamento de suas ideias, Darwin aparece como modelo de cientista, e Lamarck como um teórico especulativo. Para os autores, é "esta visão distorcida e superficial da história que vai perpetuar-se na maior parte dos livros didáticos de Biologia e nas práticas pedagógicas dos professores da área, até a atualidade” (p. 661). Uma boa história, mesmo que não verdadeira, 
pode exercer grande influência no processo de construção do conhecimento. Para Roque (2003), um motivo para a perpetuação de uma história, ainda que falsa, pode ser o fato de não estarmos habituados a questionar a autoridade dos livros. Mais uma vez evidencia-se o discurso defendido no presente artigo de como o cuidado com questões referentes à natureza e história da ciência pode influenciar, positivamente, o processo de alfabetização científica de estudantes e professores.

\section{Questão 5: Identifique as frases abaixo com $V$ (verdadeiro) e F (falso), de acordo com a teoria da evolução darwiniana:}

( ) “...o homem representa o mais complexo grau de evolução, uma vez que é capaz de produzir e utilizar ferramentas além de andar de forma bípede, mesmo que sua linhagem descenda dos hominídeos que quase não se mantinham de pé”.

( ) "De acordo com a teoria da evolução, o homem está evolutivamente conectado aos chimpanzés e gorilas porque compartilha um ancestral comum com eles; além disso, a linhagem humana sofre influência da seleção natural e do acaso".

( ) 'É natural que dentro das espécies há os seres mais e menos aptos, ou seja, aqueles que irão garantir a sobrevivência ou não das espécies. Diante dessa lógica, os seres humanos também possuem subgrupos, e, pensando em garantir o sucesso evolutivo, é importante que as anomalias genéticas ou cognitivas sejam supervisionadas de forma a garantir a sobrevivência". Sugestão de respostas:

F-Segundo a teoria da evolução, a utilização de ferramentas ou bipedalismo está associada à adaptação do Homo sapiens ao ambiente e não a qualquer condição de superioridade evolutiva. $\mathrm{V}$ - A espécie humana possui ancestral comum com gorilas e chimpanzés, conforme estudos de paleoantropologia, e, como qualquer outro organismo, está sujeito à ação do acaso e da seleção natural.

F - Não há subgrupos ou raças biológicas entre os seres humanos. As anomalias genéticas ou cognitivas podem aparecer em qualquer espécie. É graças à variabilidade genética que as populações se mantêm e garantem a sobrevivência em ambientes que mudam constantemente.

A quinta questão teve como fim analisar o entendimento dos docentes sobre a teoria da evolução em relação ao reconhecimento (i) de que não há seres vivos superiores a outros dentro de uma perspectiva evolutiva; (ii) de que há ancestralidade comum entre Homo sapiens, chimpanzés e gorilas; e (iii) de que as anomalias genéticas são comuns a todas as espécies e inerentes ao processo evolutivo, associadas à variabilidade genética, à seleção natural e ao tempo geológico dilatado.

Em sua maioria, os docentes de Ciências que responderam a esta questão demonstraram aceitar a existência de diferentes graus de superioridade na evolução, sendo o máximo alcançado pelo Homo sapiens, embora um dos respondentes compreenda que, a despeito dos níveis de complexidade estrutural apresentados pelos organismos, não há graus de superioridade entre eles e sim de adaptabilidade. Quanto aos docentes que responderam como falsa a afirmação sobre a ancestralidade comum entre seres humanos, chimpanzés e gorilas, e a influência da seleção natural e o acaso, não houve justificativa, os dois docentes 
parecem não ter claras as ideias centrais da teoria da evolução, pois ambos erraram duas questões, em relação ao referencial esperado, enquanto os demais docentes erraram apenas uma. Três dos docentes de Ciências defenderam a existência de subgrupos na espécie humana e que estes devem ser monitorados.

É possível relacionar tal posicionamento com a marcha progressiva dos hominídeos e a relação entre melhoria, progresso e eugenia, o que desperta a atenção, ao pensarmos em momentos históricos nas quais diferentes movimentos fascistas e segregacionistas sustentaram-se nesta percepção (BLANC, 1994; PAUL, 2003), um cenário que ainda assombra as sociedades humanas na segunda década do século XXI (HARARI, 2018).

Dos doze docentes de outras áreas, dois deles responderam corretamente à quinta questão e justificaram seu posicionamento conforme nossas expectativas. Oito docentes consideraram o ser humano como superior e o mais complexo degrau da evolução. Para quatro docentes, a ideia de que deve haver controle das anomalias genéticas ou cognitivas para sobrevivência da espécie é verdadeira (desconsiderando, nesse sentido, o papel fundamental do acaso e das mutações na evolução). Um deles justificou que não pode haver controle devido a fatores éticos e outro defendeu que o controle garantiria o bem-estar humano. Esta última resposta ecoa o pensamento transumanista, segundo o qual o Homo sapiens é aprimorável através do uso da ciência aplicada, capaz de aumentar sua longevidade, estender suas capacidades físicas, intelectuais e mentais (BOSTROM, 2005).

Dos dezoito docentes que responderam à questão, somente quatro apresentaram um desempenho considerado satisfatório (nenhum destes da área de Ciências). Isso sugere que a percepção generalizada que aponta para a existência de graus de superioridade entre espécies e mesmo entre indivíduos da mesma espécie é corrente mesmo entre educadores. Para Silva, Silva e Teixeira (2011), há grupos de docentes com total desconhecimento, ou notável falta de domínio, do conteúdo evolutivo - como citado acima, considerando todos os sujeitos da pesquisa (de Ciências e das outras áreas), os professores entendem a evolução como melhoramento e progresso, considerando-a de forma individual e não populacional. Essa perspectiva é compartilhada por Mota e Lira-da-Silva (2011) e Mota (2013). 
Questão 6: Numa busca pelo termo "teoria da evolução" no Google Imagens, um estudante encontrou como referência a tela com as imagens abaixo. Tomadas em conjunto, o que essas imagens dizem para você a respeito da percepção do público e acesso a informações sobre evolução?

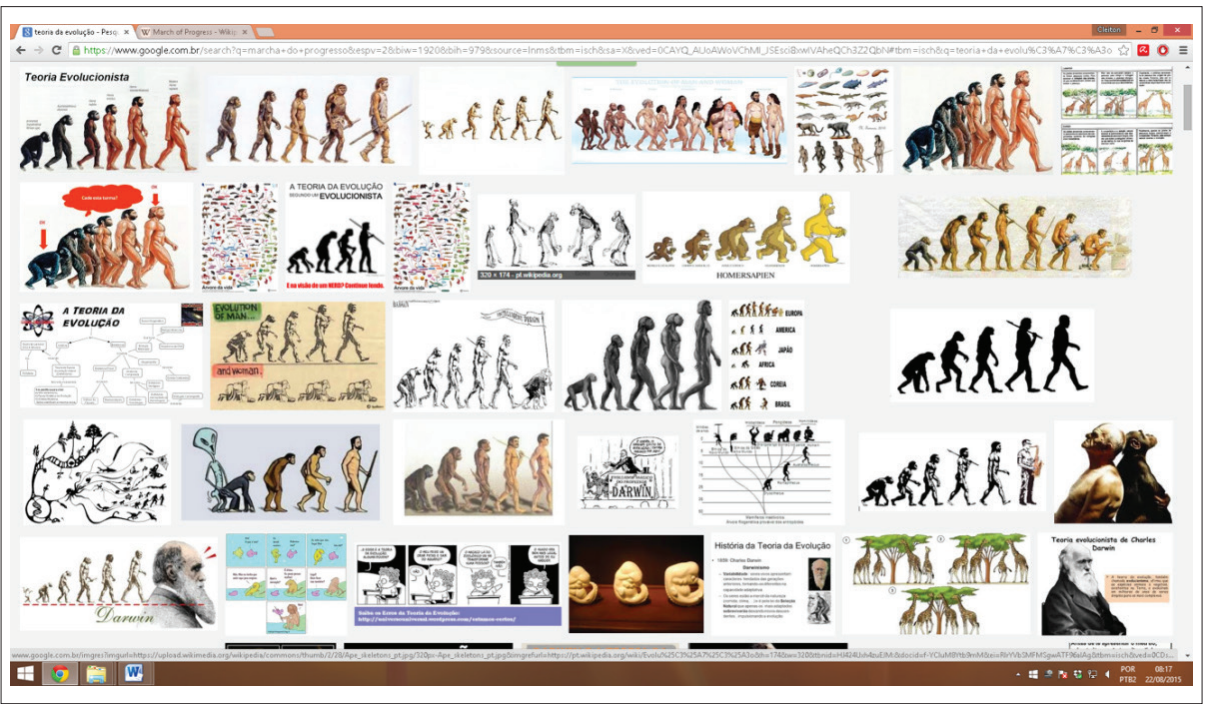

Sugestão de resposta: É preciso discernimento para identificar as fontes consultadas na internet. A marcha dos hominídeos aparece como resultado da maior parte das buscas por "teoria da evolução". Isso dissemina a confusão, especialmente para aqueles que têm pouca informação sobre o assunto. A maior parte das imagens reflete a visão equivocada do processo evolutivo: linear, necessariamente progressivo e posicionando o homem como o ápice da evolução.

A última questão apresenta um quadro de imagens obtidas através do Google Imagens (2015) em resposta à busca pelo termo "teoria da evolução". De modo geral, os docentes de Ciências compreendem que as imagens estão relacionadas com a iconografia canônica da evolução (cf. GOULD, 1990), mas não a mencionam explicitamente. A maioria parece entender que estas imagens colocam o ser humano como ápice da evolução. Somente um dos docentes de ciências mencionou a importância da reflexão e análise crítica dos resultados de buscas na internet, afirmando também que o pensamento predominante entre os alunos é de que o homem evoluiu do macaco (o que reforça nossa hipótese de que a marcha dos hominídeos influencia a percepção sobre o homem e a natureza). Um dos docentes afirmou, sem questionar seu conteúdo subjacente pernicioso, que estas imagens representam uma forma lúdica para assimilação da teoria da evolução.

Quanto aos docentes das demais áreas, alguns afirmaram que a busca por informação sem conhecimento científico implica na aceitação de imagens de senso comum como sendo de fato científicas. Um deles mencionou a linearidade vista nas imagens e outro apontou para duas imagens, dentre as apresentadas na questão, que representam acertadamente a teoria evolutiva. Parte dos docentes, no entanto, não compreende que as imagens resultantes da busca do Google são no geral representações equivocadas acerca da teoria. 
A marcha dos hominídeos é uma imagem tão forte e disseminada que sua veracidade enquanto representação da teoria evolutiva sequer é questionada por muitos docentes, o que vai ao encontro da perspectiva assumida no presente trabalho. Idealmente, ao menos parte dos docentes deveria mencionar a importância da alfabetização científica sobre o assunto de modo a orientar uma correta seleção das informações resultantes de mecanismos de busca. Contudo, as respostas dadas à questão seis reforçam a necessidade de levar este assunto para um patamar além do teórico, pensando em ações de formação docente continuada e reestruturação das orientações complementares aos PCN, que precisam levar em conta as novas tecnologias de informação (BRASIL, 2002).

\section{CONSIDERACְ̃̃ES FINAIS}

Por muitos séculos, acreditou-se que o Homo sapiens estava em algum lugar entre os animais e os anjos, sendo um descendente direto de Deus (DI MARE, 2002; BOWLER, 2009). Como as imagens são muitas vezes mais diretas que as palavras (MASON, 2006; TOMIO et al., 2013), elas por vezes facilitam a disseminação de interpretações equivocadas de conceitos científicos. Para Gould (1990), as iconografias mais conhecidas da evolução embutem a percepção de que a superioridade humana é inevitável, promovendo a ideia do homem caucasiano europeu como ápice do processo evolutivo. A marcha do progresso está presente em todos os meios de comunicação e é acessível para virtualmente todas as pessoas, seja em pesquisas por palavras-chave realizadas no Google, em anúncios publicitários, livros didáticos, filmes ou animações.

Ainda que a percepção sobre a evolução biológica tenha avançado muito desde Darwin (1859), nota-se no discurso de educadores de diferentes áreas uma forte herança de concepções equivocadas e progressivas: muitos ainda creem na existência de diferenças, inclusive intelectuais, entre populações de Homo sapiens (GIAROLA, 2010; AGUILAR FILHO, 2011), continuam a considerar o homem como "o ser vivo mais evoluído dentre todos" ou mesmo pensam que o homem descende diretamente do macaco (BOWLER, 2009). Algumas das respostas discutidas aqui, dadas por professores de Ciências e de outras áreas do Ensino Fundamental, reforçam essa percepção.

Os resultados discutidos no presente trabalho corroboram a hipótese inicial de que a iconografia da evolução - a marcha progressiva dos hominídeos - continua presente na realidade escolar e é poucas vezes desconstruída no discurso dos docentes. Dentro do universo amostral da presente pesquisa, foram poucos os docentes que reconheceram a imagem como uma forma equivocada de representação da teoria evolutiva e a discutiram com alguma profundidade conceitual.

Se o docente considera a marcha do progresso correta, por conseguinte é provável que interprete o mundo natural enfatizando a competição, a substituição de "mais simples" por "mais evoluídos", e defendendo slogans do tipo "sobrevivência do mais forte". 
O problema das falsas concepções a respeito da teoria evolutiva e de como ela é tratada em sala de aula, em diferentes níveis, não é exclusivo do Brasil ou dos níveis de Ensino Fundamental e Médio. Há inúmeros estudos recentes apontando o quão comum é a apresentação de posições equivocadas sobre o ensino da evolução biológica, desde a reiteração de concepções como a de que nossa espécie "evoluiu de macacos, gorilas e chimpanzés", até ideias que ecoam a iconografia progressiva da evolução dos hominídeos, discutida no presente artigo, e a perspectiva subjacente de que a evolução sempre resulta em melhorias e no aumento da complexidade dos sistemas biológicos (PET'TO; MEAD, 2008; GREGORY, 2009; PAZZA; PENTEADO; KAVALCO, 2009; ANDREWS; KALINOWSKI; LEONARD, 2011; YATES; MAREK, 2014).

A disseminação desses pontos de vista por parte de professores em qualquer nível da educação formal mostra a necessidade de reavaliar a formação científica docente, que exige, para além da compreensão dos conteúdos técnicos das diferentes áreas do conhecimento, também uma visão ampla do contexto histórico, social e filosófico das ciências, inclusive agregando diferentes espaços formativos na formação docente inicial, como museus e centros de ciências. Os museus, como espaços de educação e cultura, também têm se legitimado na realização de ações de formação docente inicial e continuada (MARANDINO, 2014; PUGLIESE, 2015; PUGLIESE; MARANDINO, 2018), e suas exposições contribuem para viabilizar práticas interdisciplinares, especialmente cenários expositivos de museus de História Natural, que abarcam temas e conceitos referentes à teoria da evolução.

Cientistas que não avaliam questões históricas e sociais incorrem no risco de repetir atrocidades do passado (SANTOS, 2015). Educadores não atentos para a necessidade da compreensão do mundo sob a ótica evolutiva, no sentido de ampliar os horizontes de conhecimento dos educandos e posicioná-los lado a lado das outras espécies com as quais eles coabitam o planeta, estimulam a manutenção da ordem exploratória que nos é tão comum. Ao analisarmos o atual momento histórico, social e político, não é difícil reconhecer que esse discurso de superioridade é muito presente - de fato, ele tem ganhado adeptos em diferentes estratos sociais, e têm funcionado como fundamentação para o avanço da xenofobia, racismo e misoginia mesmo em países ditos desenvolvidos (HARARI, 2018). Os discursos de ódio corriqueiramente identificados em eventos esportivos, perfis na internet e redes sociais são alguns dos inúmeros exemplos que ameaçam inclusive a manutenção de instituições e estruturas democráticas (BARTLET'T, 2018).

Para Smith (2010), cabe aos professores oferecer experiências de aprendizado que apresentem aos alunos oportunidades para entender os preceitos da teoria evolutiva; a compreensão correta desta teoria é a base efetiva para tomada de decisões no mundo real.

Em nossa percepção, é importante que os professores de todas as áreas da Educação Básica, incluindo as do Ensino Fundamental, Ensino Médio e da Educação de Jovens e Adultos, sejam contemplados com uma formação interdisciplinar, discutindo ciência em um contexto sócio-histórico-econômico, pois é inegável que as dúvidas de docentes ou educandos permeiam todas as áreas e idades. Mesmo o eixo ecológico-evolutivo sendo considerado pelos PCN (BRASIL, 1998, 2002) 
como integrador das ciências, foi possível constatar, através do presente trabalho, que essa é uma realidade pouco difundida no sistema de ensino brasileiro.

Estudos que apresentem dados e análises de práticas pedagógicas interdisciplinares no contexto da teoria evolutiva, que tratem do engajamento dos estudantes, envolvendo diferentes espaços educativos, assim como propostas de formação de professores com essa temática, ainda são incipientes na área de pesquisa em Educação em Ciências. Seria um contrassenso pensar em mudança de perfil conceitual, em engajamento de estudantes, em diferentes frentes de tomada de decisão, em um ensino de Ciências com enfoque em Ciência, Tecnologia, Sociedade e Ambiente, em processos contínuos de alfabetização científica sem considerar todas essas perspectivas também na formação de professores. $\mathrm{O}$ diagnóstico aqui apresentado pode funcionar como ponto de partida para melhorar esse quadro.

\section{AGRADECIMENTOS}

Os autores gostariam de agradecer à Meiri A. G. C. Miranda (UFABC) e Rosana L. F. Silva (USP) pela leitura e sugestões de uma versão anterior do presente texto. O presente trabalho foi realizado com apoio da Coordenação de Aperfeiçoamento de Pessoal de Nível Superior - Brasil (CAPES) - Código de Financiamento 001, CNPq (305630/2016-4; 406088/2018-7) e FAPESP (2017/11768-8; 2018/13550-2).

\section{REFERÊNCIAS}

AGUILAR FILHO, S. Educação, autoritarismo e eugenia: exploração do trabalho e violência à infância desamparada no Brasil (1930-1945). Tese (Doutorado em Educação), Faculdade de Educação, Universidade Estadual de Campinas, Campinas, 2011.

ALMEIDA, A. V.; FALCÃO, J. T. R. As teorias de Lamarck e Darwin nos livros didáticos de Biologia no Brasil. Ciência \& Educação, v. 16, n. 3, 649-665, 2010.

ANDREWS, T. M.; KALINOWSKI, S. T.; LEONARD, M. J. Are Humans Evolving? A Classroom Discussion to Change Student Misconceptions Regarding Natural Selection. Evolution: Education and Outreach, 4, 343, 2011. https://doi.org/10.1007/s12052-011-0343-4

BARTLETT, J. The People vs Tech: how the internet is killing democracy (and how we save it). Londres: Ebury Digital, 2018.

BAUM, D. A.; SMITH, S. D.; DONOVAN, S. S. S. The Tree-Thinking Challenge. Science, 310, 979-980, 2005.

BIZZO, N. M. V. Ensino de Evolução e história do darwinismo. Tese (Doutorado em Educação) - Faculdade de Educação, Universidade de São Paulo, São Paulo, 1991.

BLANC, M. Os Herdeiros de Darwin. São Paulo: Ascritta, 1994.

BOSTROM, N. In defence of posthuman dignity. Bioethics, v. 19, n. 3, 202-214, 2005.

BOWLER, P. J. Evolution: the history of an idea. 25. Los Angeles: University Of California Press, 2009. 
BRASIL. MEC. Parâmetros Curriculares Nacionais para o Ensino Médio: Ciências da Natureza, Matemática e suas Tecnologias. Brasília, 1998.

BRASIL. Secretaria de Educação Média e Tecnológica (Semtec). PCN + Ensino médio: orientações educacionais complementares aos Parâmetros Curriculares Nacionais - Ciências da Natureza, Matemática e suas Tecnologias. Brasília: MEC/Semtec, 2002.

BIZOTTO; F. M.; GHILARDI-LOPES, N. P.; SANTOS, C. M. D. A vida desconhecida das plantas: concepções de alunos do Ensino Superior sobre evolução e diversidade das plantas. REEC. Revista Electrónica de Enseñanza de las Ciencias, v. 15, p. 394-411, 2016.

CAMPOS, P. J.; CRISPIM, A.; VELEZ. E. Colonialismo ficção e drama: duas vertentes da "civilização" do séc. XIX. Disponível em: <http://www.historia.uff.br/nec/colonialismo-ficcao-edrama-duas-vertentes-da-civilizacao-do-sec-xix>. Acesso em: 10 fev. 2016.

DARWIN, C. On the origin of species by means of natural selection or the preservation of favored races in the struggle for life. London: Murray, 1859.

DI MARE, R. A. A concepção da teoria evolutiva desde os gregos: ideias, controvérsias e filosofias. Porto Alegre: EDIPUCRS, 2002.

EL-HANI, C. N.; MEYER, D. A evolução da teoria darwiniana. Com Ciência, 107, 2009.

GIAROLA, F. R. Racismo e teorias raciais no século XIX: principais noções e balanço historiográfico. História e-História, v. SM, p. 1-21, 2010.

GIL PÉREZ, D.; MONTORO, I. F.; ALÍS, J. C.; CACHAPUZ, A.; PRAIA, J. Por uma imagem não deformada do trabalho científico. Ciência \& Educação, v. 7, n. 2, 125-153, 2001.

GOOGLE. Pesquisa em imagens: teoria da evolução, 2015. Disponível em: <https://bit. ly/2BcxnIV>. Acesso em: 22 jul. 2015.

GOULD, S. J. Vida Maravilhosa: o acaso na evolução e na natureza da história. São Paulo: Companhia das Letras, 1990.392 p.

GOULD, S. J. Pilares do Tempo: Ciência e religião na plenitude da vida. Rio de Janeiro: Rocco, 2002. 185p.

GREGORY, T. R. Understanding Natural Selection: Essential Concepts and Common Misconceptions. Evolution: Education and Outreach, 2, 128. 2009. https://doi.org/10.1007/ s12052-009-0128-1

HARARI, Y. N. 21 lessons for the 21st Century. Londres: Jonathan Cape, 2018.

HOBSBAWM, E. A era do capital (1848-1875). $3^{a}$ edição. Rio de Janeiro: Paz e Terra, 1981.

HUXLEY, T. H. Evidence as to Man's Place in Nature. Londres: Williams \& Norgate, 1863.

IBOPE. Pesquisa de opinião pública sobre o criacionismo. Rio de Janeiro, 2004. 26 p. Disponível em: <http://www.ibope.com.br/pt-br/conhecimento/relatoriospesquisas/lists/ relatoriospesquisaeleitoral/opp\%20040992\%20-\%20criacionismo.pdf>. Acesso em: 30 jul. 2015.

MARANDINO, Martha. Espaços não formais no contexto formativo. In: BARZANO, M. A. L.; FERNANDES, J. A. B.; FONSECA, L. C. S.; SHUVARTZ, M. (org.). Ensino de Biologia: experiências e contextos formativos. Goiânia, p. 169-180, 2014. 
MASON, R. Reading Scientific Images: the iconography of evolution. Cidade do Cabo: HSRC press, 2006.

MAYR, E. Uma Ampla Discussão. Charles Darwin e a Gênese do Moderno Pensamento Evolucionista. Ribeirão Preto: FUNPEC Editora, 2006.

MORTIMER, E. F. Construtivismo, Mudança Conceitual e Ensino de Ciências: Para Onde Vamos?. Investigações em Ensino de Ciências, 1(1), 20-39, 1996.

MORTIMER, E. F.; CARVALHO, A. M. P. Referenciais teóricos para análise do processo de ensino de ciências. Cadernos de Pesquisa, 96, 5-14, 1996.

MOTA, H. S. Evolução biológica e religião: atitudes de jovens estudantes brasileiros. Tese (Doutorado em Educação), Faculdade de Educação, Universidade de São Paulo, São Paulo, 2013.

MOTA, P. S.; LIRA-DA-SILVA, R. M. Representações do Pensamento Evolutivo de Estudantes e Professores: Uso de Ferramentas Educativas do Projeto Darwin Now. In: I Congreso Iberoamericano de Investigación en Enseñanza de las Ciencias - VIII Encontro Nacional de Pesquisa em Educação em Ciências, 2011.

MOURA, J. C. S.; SILVA-SANTANA, C. C. A evolução humana sob a ótica do professor do ensino médio. Revista Metáfora Educacional. Feira de Santana, 13, 93-108, 2012.

OLEQUES, L. C.; SANTOS, M. L. B.; BOER, N. Evolução biológica: percepções de professores de Biologia. Revista Electrónica de Enseñanza de las Ciencias, v. 10, n. 2, 243-263, 2011.

PAUL, D. Darwin, social Darwinism and eugenics. In: J. HODGE; G. RADICK (ed.), The Cambridge Companion to Darwin, p. 214-239. Cambridge: Cambridge University Press, 2003.

PAZZA, R.; PENTEADO, P. R.; KAVALCO, K. F. Misconceptions About Evolution in Brazilian Freshmen Students. Evolution: Education and Outreach, 3, 187, 2009. https://doi.org/10.1007/ s12052-009-0187-3

PEREIRA, H. M. R. Um olhar sobre a dinâmica discursiva em sala de aula de biologia do ensino médio no contexto do ensino da evolução biológica. 166 fls. Dissertação (Mestrado em Ensino, Filosofia e História das Ciências), Universidade Federal da Bahia, Universidade Estadual de Feira de Santana, Salvador, 2009.

PETTO, A. J.; MEAD, L. S. Misconceptions About the Evolution of Complexity. Evolution: Education and Outreach, 1, 82, 2008. https://doi.org/10.1007/s12052-008-0082-3

PUGLIESE, A. Os museus de ciências e os cursos de licenciatura em Ciências Biológicas: o papel desses espaços na formação inicial de professores. 2015. 231f. Tese (Doutorado em Educação) - Faculdade de Educação, Universidade de São Paulo (FEUSP), São Paulo, 2015.

PUGLIESE, A.; MARANDINO, M. Museu como espaço legítimo na formação docente em Ciências Naturais. In: BARBOSA, Marinalva Vieira; COSTA, Váldina Gonçalves. (org.). Formação de professores e contextos de trabalho: diferentes olhares. 1ed.Campinas: Mercado de Letras, 2018, p. 119-134.

ROQUE, I. R. Sobre girafas, mariposas, corporativismo científico e anacronismos didáticos. Ciência Hoje, São Paulo, v. 34, n. 200, p. 64-67, 2003.

SANTOS, C. M. D. O hipopótamo de Tal: reflexões sobre o conhecimento científico. 1. ed. São Paulo: Métis Produção Editorial, 2015. 136p. 
SANTOS, C. M. D.; CALOR, A. R. Using the logical basis of phylogenetics as the framework for teaching biology. Papéis Avulsos de Zoologia, 48, 199-211, 2008

SANTOS, C. M. D.; KLASSA, B. Despersonalizando o ensino de evolução: ênfase nos conceitos através da sistemática filogenética. Educação: Teoria e Prática, 22, 40, 62-81, 2012.

SASSERON, L. H.; CARVALHO, A. M. P. Almejando a alfabetização científica no Ensino Fundamental: A proposição e a procura de indicadores do processo. Investigações em Ensino de Ciências, v. 13, n. 3, 333-352, 2008.

SASSERON, L. H.; CARVALHO, A. M. P. Alfabetização Científica: Uma revisão bibliográfica. Investigações em Ensino de Ciências, v. 16, n. 1, 59-77, 2011.

SMITH, M. U. Current Status of Research in Teaching and Learning Evolution: I. Philosophical/ Epistemological Issues. Science \& Education, v. 19, n. 6-8, 523-538, 2010.

SILVA, H. M.; SILVA, P. R.; SOUZA, A. C. L.; ARAÚJO, E. S. N. N. A influência da religiosidade na aceitação do evolucionismo: um estudo em uma amostra da população brasileira. Conexão Ciência. Formiga, v. 8, n. 1, 01-19, 2013.

SILVA, M. G. B; SILVA, R. M. L.; TEIXEIRA, P. M. M. A evolução biológica na formação de professores de Biologia. In: Congreso Internacional de Investigación en Enseñanza de las Ciencias, 1. Campinas: Abrapec, 2011.

TEIXEIRA, F. M.; SOBRAL, A. C. M. B. Como novos conhecimentos podem ser construídos a partir dos conhecimentos prévios: um estudo de caso. Ciência \& Educação, v. 16, n. 3, p. 667-677, 2010.

TIDON, R.; LEWONTIN, R. C. Teaching evolutionary biology. Genetics and Molecular Biology, v. 27, n. 1, 124-131, 2004.

TOMIO, D. et al. As imagens no ensino de ciências: o que dizem os estudantes sobre elas? Caderno Pedagógico, Lajeado, v. 10, n. 1, 25-40, 2013.

TOWBIN, M. A.; HADDOCK, S. A.; ZIMMERMAN, T. S.; LUND, L. K.; TANNER, L. R. Images of gender, race, age, and sexual orientation in Disney feature-length animated films. Journal of Feminist Family Therapy, v. 15, n. 4, 19-44, 2003.

VALENÇA, C. R.; FALCÃO, E. B. M. Teoria da evolução: Representações de professorespesquisadores de biologia e suas relações com o ensino médio. Revista Electrónica de Enseñanza de las Ciencias, v. 11, n. 2, 471-486, 2012.

YATES, T.B.; MAREK, E. A. Teachers teaching misconceptions: a study of factors contributing to high school biology students' acquisition of biological evolution-related misconceptions. Evolution: Education and Outreach, 7, 7, 2014. https://doi.org/10.1186/s12052-014-0007-2

Submetido em 08/10/2018

Aprovado em 05/06/2019

\section{Contato:}

Charles Morphy D. Santos

Universidade Federal do ABC

Avenida dos Estados, 5001 - Bairro Santa Terezinha

CEP 09.210-580 - Santo André, SP - Brasil 